\title{
Una nueva oportunidad para estudiar: Sentido y significados del SUA
}

Mtra. Artemisa Espinosa Olivares*

* Profesora Titular "A" T.C. Coordinadora de Metodologías, Materiales y Medios Educativos de la División Sistema Universidad Abierta de la ENEO.

Estudiar forma parte "natural" en la vida de muchos niños, niñas y adolescentes. Las familias y la sociedad en su conjunto encomiendan a la escuela la formación de los hijos, su preparación para la vida y el trabajo; así van dejando su huella los niveles escolares básicos: preprimaria, primaria, secundaria... en aquellos que lograron permanecer.

Estudiar bachillerato y una carrera universitaria ha sido para muchas personas un sueño inalcanzable, por su imperiosa necesidad de incorporarse al mercado laboral: había que ayudar o sostener a la familia. Esta situación ha sido mas acuciante para las mujeres, que insertas en estereotipos culturales, sociales y familiares vieron mas restringidas sus oportunidades para estudiar. Es el caso de un importante sector de auxiliares que forman parte de los recursos de salud y que dan cobertura significativa de servicios de salud en todos los niveles de atención. Ellas han sido las primeras destinatarias de los servicios educativos que ofrece la División Sistema Universidad Abierta (SUA) de la Escuela Nacional de Enfermería y Obstetricia (ENEO).

\section{¿Cómo dar una nueva oportunidad para estudiar a mujeres adultas que trabajan?}

El SUA ha respondido de manera efectiva a este complejo proyecto de profesionalización. El sentido de existencia del SUA está precisamente allí, en la filosofía que le dio origen al sistema y que en palabras del Dr. Pablo González Casanova fue el de extender la educación superior a un mayor número de personas, permitiendo a la Universidad ir a los centros de producción y de servicios, para satisfacer la necesidad de una población, de hacer estudios universitarios y que por razones de trabajo no lo podría hacer en forma escolarizada.

La experiencia de muchos años y los resultados obtenidos, permitió abrir -a través de esta modalidad educativa- otro espacio de formación a otro sector de Enfermería: Enfermeras técnicas que aspiraban a lograr el grado de Licen- ciatura en esta disciplina, sin desarraigarse de su lugar de origen y combinando el estudio con el trabajo.

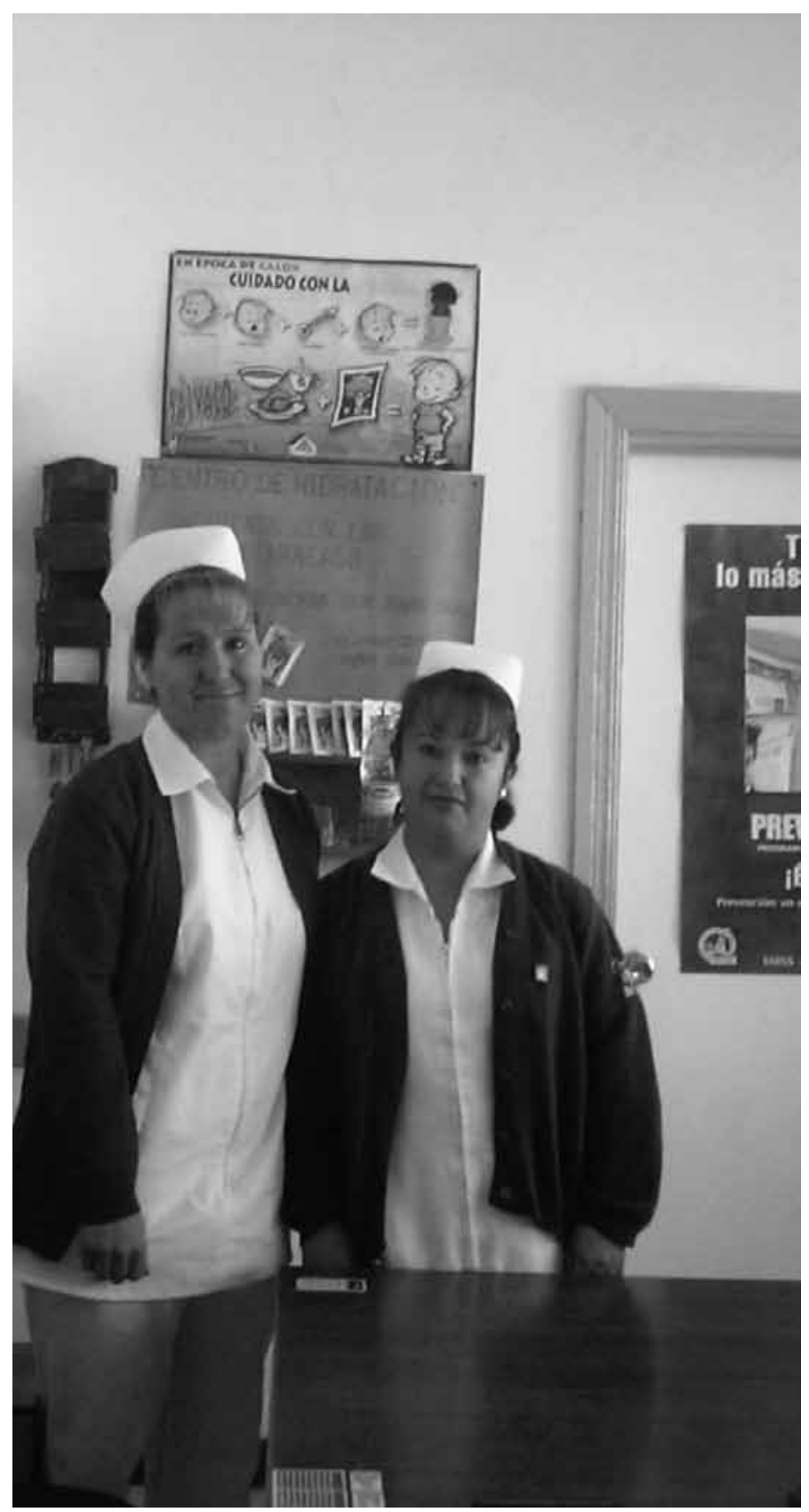




\section{¿Cuáles han sido los significados del SUA?}

A mi juicio, muchos y en distintas dimensiones:

- A nivel personal el SUA ha significado para cada alumna y alumno, una segunda oportunidad para estudiar, para crecer profesionalmente y iporqué no? para crecer como persona.

- Ha significado la posibilidad de movilidad social, de tener mejores oportunidades de trabajo, de mayor reconocimiento profesional.

- A nivel institucional el SUA ha significado en muchas instituciones de salud, un proyecto universitario que favorece la profesionalización del personal de Enfermería.

- $\quad$ Para las instituciones de salud ha significado contar con personal profesional que ofrece una atención de calidad.

- $\quad$ En la ENEO, como institución educativa de vanguardia en la formación de recursos de Enfermería en el país, ha significado la posibilidad de ampliar su oferta educativa a todo el país, ya que prácticamente no hay estado de la República Mexicana donde no exista una sede del SUA ENEO sea del nivel técnico o de Licenciatura.

- $\quad$ Significa para nuestra Escuela un programa estratégico de profesionalización de Enfermería que apoya y consolida al gremio de Enfermería y que es reconocido por la OPS por los beneficios que aporta al sector salud y a la profesión.

- $\quad$ Significa para el SUA de la ENEO un compromiso moral y de justicia social para cada Enfermera trabajadora, auxiliar o técnica, que sueña con volver a estudiar y que de no ser por esta opción educativa, sus sueños sólo serían eso, y no una realidad que se ha dado en cada alumna y alumno que ha formado parte de treinta generaciones de nivel técnico y diecinueve generaciones de nivel Licenciatura.

- $\quad$ Significa para los docentes que trabajan o participan en esta modalidad, en un interés genuino por los aprendizajes de los estudiantes, estén cercanos o lejanos geográficamente de nosotras, que se manifiesta en el trabajo cotidiano que realizamos, en las asesorías, en los libros y materiales que producimos; en el permanente deseo de mejorar y actualizar estos materiales que les ofrecemos.

- A nivel social el significado implícito y latente es el contar con Enfermeras profesionales que ofrecen cuidados a la salud de los individuos, familias y comunidades, más certeros, más profesionales y más humanísticos.

- $\quad$ En síntesis, el significado del SUA se puede traducir en un entramado de sueños que se entretejen con cada generación que ingresa y que se convierten en realidad con el esfuerzo conjunto de todos sus actores. Bienvenidas sean!!

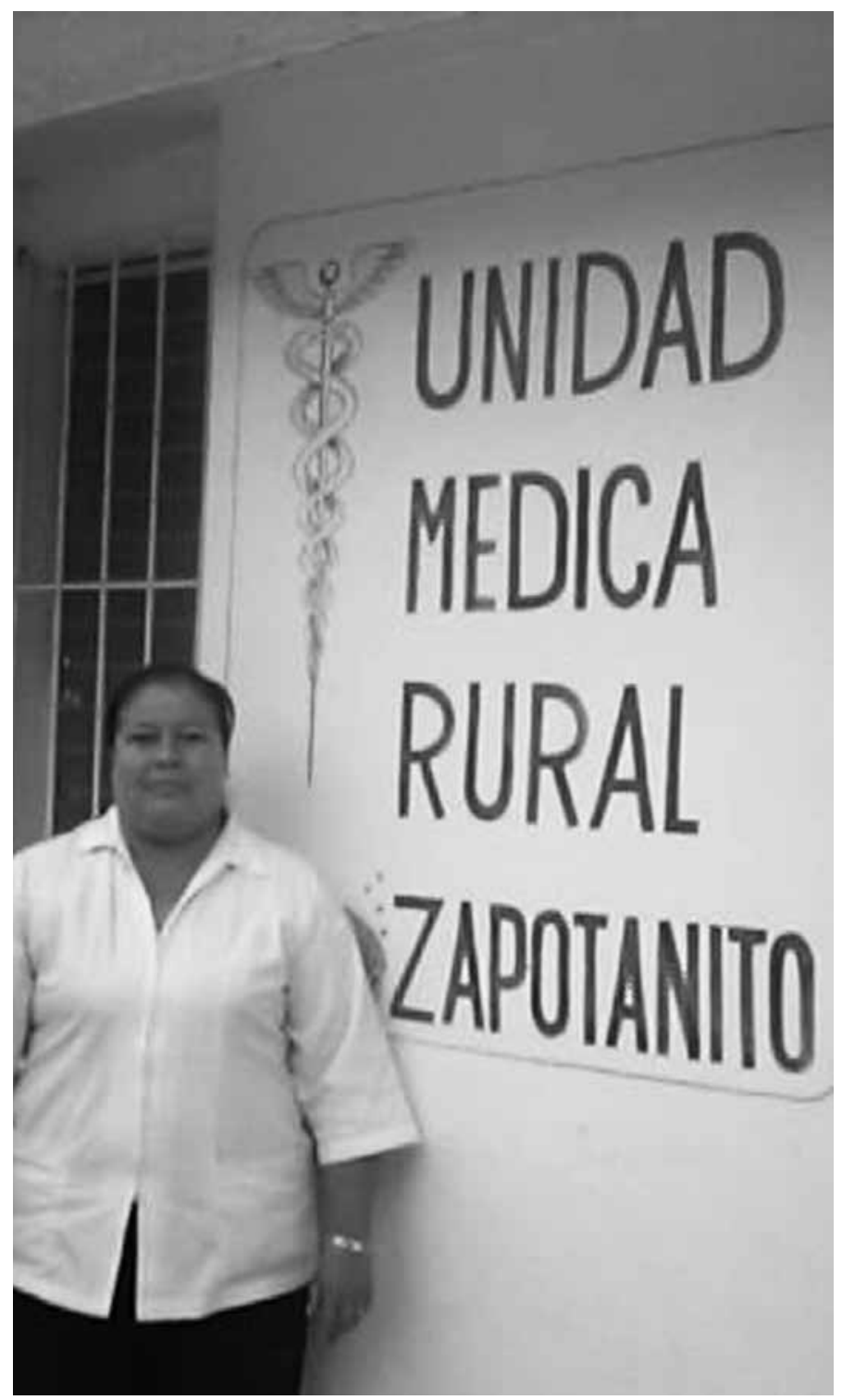

